\title{
FAKTOR-FAKTOR YANG MEMPENGARUHI PRODUKTIFITAS LEGISLASI DPRD KABUPATEN GARUT PERIODE 2014-2019
}

\author{
Selvi Centia ${ }^{1}$, Ida Widianingsih ${ }^{2}$, Moh. Benny Alexandri ${ }^{3}$ \\ Fakultas Ilmu Sosial dan Ilmu Politik \\ Universitas Padjajaran \\ selvicentia33@gmail.com, ida.widianingsih@unpad.ac.id, bennyalexandri@yahoo.co.id
}

\begin{abstract}
ABSTRAK
Dalam fungsi legislasi DPRD memiliki fungsi membuat peraturan daerah, melalui fungsi ini DPRD berada pada posisi yang sangat berpengaruh terhadap kelangsungan masa depan daerah , maka dari itu dalam pelaksanaan fungsi legislasi ini di perlukan produktifitas DPRD yang maksimal. . Tetapi dalam kenyataan nya fungsi ini tidak berjalan maksimal . DPRD kabupaten Garut dinilai kurang produktif karena sedikitnya Rancangan Perda yang diajukan atas inisiatif dewan. Kurang optimalnya fungsi legislasinya yang dijalankan DPRD Kabupaten Garut karena di sebabkankan oleh beberapa faktor , mulai dari rekrutmen calon anggota legislatif oleh partai politik yang tidak memperhatikan tingkat pendidikan dan pengalaman sebagai calon wakil rakyat, kurangnya skill yang di miliki anggota DPRD dalam merancang Perda, dan tidak ada ketaataan mengenai mekanisme kerja terkait tugas sebagai DPRD. Selain itu faktor kerjasama diantara para anggota DPRD terjadi Tarik menarik antara kepentingan partai politik yang berpengaruh terhadap perda yang dihasilkan.
\end{abstract}

Kata Kunci : Dewan Perwakilan Rakyat Daerah, Fungsi Legislasi

\begin{abstract}
In the legislative function the DPRD has the function of making regional regulations, through this function the DPRD is in a position that is very influential on the continuity of the future of the region, therefore the implementation of the legislative function requires maximum productivity of the DPRD. . But in reality this function does not work optimally. Garut Regency DPRD is considered less productive because at least the Draft Perda was submitted at the initiative of the council. The lack of optimal legislative functions carried out by the Garut Regency DPRD is caused by several factors, starting from the recruitment of legislative candidates by political parties who do not pay attention to the level of education and experience as candidate representatives, lack of skills that DPRD members have in drafting regulations, and not there is compliance with the work mechanism related to the task as a DPRD. In addition, a factor of cooperation among DPRD members occurs between the interests of political parties that influence the regulations produced
\end{abstract}

Keyword : Houseof Representatives, the legislative function

\section{Pendahuluan}

Gerakan repformasi 1988 telah membawa angin perubahan terhadap penyelengaraan pemerintahan di Indonesia. Sistem pemerintahan yang sentralistik dengan Undang-Undang No 5 tahun 1974 tentang pokok-pokok Pemerintahan Daerah digantikan dengan sistem pemerintahan desentralisasi tentang Pemerintahan Daerah . Sesuai dengan amanat UndangUndang Dasar Negara Republik Indonesia Tahun 1945 dan Undang-Undang Nomor 23 tahun 2014 tentang Pemerintahan Daerah, daerah otonom berwenang mengatur dan mengurus sendiri urusan pemerintahan. Pemberian wewenang tersebut bertujuan untuk mewujudkan suatu pemerintahan yang efektif dan efisien.
Salah satu prinsip dasar otonomi daerah menurut UU No 23 tahun 2014 tentang Pemerintahan Daerah adalah pelaksanaan otonomi daerah harus lebih meningkatkan peran dan fungsi badan legislatif daerah baik fungsi legislasi, pengawasan maupun fungsi anggaran atas penyelenggaraan pemerintahan daerah.

Dalam fungsi legislasi DPRD memiliki fungsi membuat peraturan daerah, melalui fungsi ini DPRD berada pada posisi yang sangat berpengaruh terhadap kelangsungan masa depan daerah , maka dari itu dalam pelaksanaan fungsi legislasi ini di perlukan produktifitas DPRD yang maksimal. Secara umum dikatakan bahwa kinerja anggota legislatif relatif rendah, citra buruk ini terjadi bukannya hanya dalam tingkat pusat melainkan terjadi juga di tingkat DPRD tingkat Kabupaten/Kota. 
Hasil riset yang dilakukan beberapa lembaga survei bahwa masyarakat merasa tidak puas. Hasil survey yang dilakukan dari tanggal 23-26 Agustus 2018 dilakukan dengan cara mewawancarai terhadap 800 orang responden di kota besar Medan, Palembang, Jakarta , Bandung, Semarang, Yogyakarta, Surabaya, Makasar. Hasil penelitian. bahwa 20,3\% responden menilai kinerja DPR dibidang legislasi tak berjalan optimal . ${ }^{1}$

Berdasarkan pengamat penulis menunjukan pelaksanaan fungsi legislasi DPRD Kabupaten Garut , jika di lihat dengan cermat belum dapat melaksanakaan fungisnya secara optimal , terutama dalam menyusun perda untuk setiap tahun anggran dengan mempertimbangkan masukan dari Pemda serta memberikan pertimbangan terhadap Perda yang diajukan anggota dalam tahun berjalan atau diluar Perda yang terdaftar dalam program legislasi daerah. Hal tersebut diperkuat dengan hasil wawancara dengan salahsatu anggota DPRD mengenai rekapitulasi Perda Kabupaten Garut tahun 2015 -2016 , dapat diketahui bahwa Perda baik yang di usulkan pemerintah daerah maupun inisiatif dewan dari tahun 2015-2016 tidak mencapai target bahkan terjadi penurunan beberapa persen . Hal tersebut menunjukan rendahnya peran anggota DPRD Kabupaten Garut dalam melaksanakan fungsi legislasi, menyebab kan banyak Perda yang belum dibahas, sehingga hal tersebut membuat Perda harus dibahas dan di tetapkan tahun berikutnya yang belum tentu sesuai dengan kebutuhan pada tahun tersebut dan tepat sasaran mengingat kondisi masyarakat yg semakin berubah seiringnya waktu. Semakin banyak perda yang diajukan semakin banyak juga Perda yang tidak di bahas.

Dalam menjalankan fungi legislasi DPRD Kabupaten Garut periode 2014-2019 dianggap sangat kurang optimal bila dibandingkan dengan fungsi DPRD lainnya. Masalah dari kurang optimalnya fungsi legilasi terjadi pada kurang nya produktifitas anggota DPRD karena keterbatasan kemampuan yang dimiliki.

Berdasarkan uraian diatas ternyata DPRD di daerah pun tidak jauh berbeda dengan DPR pusat menyangkut pelaksanaan fungsi legislasi sehingga menimbulkan minat penulis untuk mengakaji dan meneliti tentang Faktor-faktor yang mempengaruhi produktivitas DPRD Kabupaten Garut dalam melaksanakan fungsi legislasi periode tahun 20142019.

\section{Metode Penelitian}

Penelitian ini menggunakan metode kualitatif dengan pendekatan studi pustaka, melalui kajian literatur yang terkait dengan pelaksanaan fungsi

\footnotetext{
${ }^{1}$ IFES Indonesia ,Survei , pada Agustus 2018
}

legislasi DPRD. Sumber data yang digunakan berupa sumber data yang berasal dari teks berupa buku, jurnal, media cetak, elektronik dan online yang berkaitan dengan masalah.

Dalam penelitian ini akan digambarkan secara lebih rinci tentang faktor-faktor yang mempengaruhi produktifitas legislasi DPRD Kabupaten Garut periode 2014-2019 . Subjek dalam penelitian ini adalah anngota DPRD Kabupaten Garut . Teknik pengumpulan data dilakukan inventarisasi data primer dan sekunder. Data primer diperoleh melalui wawancara mendalam observasi non-partisipan serta diskusi kelompok terarah. Sedangkan data sekunder diperoleh melalui literature baik dari dokumen pemerintah, media cetak dan elektronik jurnal dan buku terkait kemitraan dan pemberdayaan.

\section{Pembahasan}

Berdasarkan Undang-Undang nomor 27 tahun 2009 tentang susunan dan kedudukan MPR dan DPR serta DPD dan DPRD, menyebutkan DPRD mempunyai fungsi legislasi, anggaran dan pengawasan.

Menurut Jimly Assisiqie, fungsi DPRD sebagai legislatif menyangkut empat kegiatan, yaitu : (1) Prakarsa pembuatan undang-undang (legislative intation); (2) pembahasan rancangan Undang-Undang ( law making process); (3) persetujuan atas pengesahan rancangan undang-undang (law enactement approval); (4) pemberian persetujuan pengikatan atau persetujuan internasional dan dokumen hukum yang mengikat lainnya. $^{2}$

Dari beberapa kajian tentang kinerja DPRD menunjukan bahwa fungsi DPRD dianggap belum optimal terutama dalam pelaksanaan fungsi legislasi.

Anggota DPRD garut periode 2014-2019 pun dianggap belum berhasil dalam pelaksanakan fungsi legislasinya . Hal ini terlihat dari hasil produk legislasinya,

Faktor-faktor yang menghambat produktifitas DPRD dalam melaksanakan fungsi legislasi . diantaranya :

1. Sumber Daya Manusia (SDM)

a. Pendidikan

Tingkat pendidikan anggota DPRD kabupaten Garut dinilai sudah cukup memenuhi kriteria dan periode ini relative lebih baik dibandingkan dengan periode-periode sebelummya yaitu rata-rata lulusan S1 . Namun dari segi jurusan menurut penulis belum memenuhi kriteria karena kebanyakan bukan berlatar belakang pendidikan yang mempunyai kemampuan memahami UU. Sehingga

\footnotetext{
2 Jimly Assiddiqie. Pengantar Ilmu Tata Negara. Jakarta: PT Raja Grafindo Persada. 2009
} 
mengakibat kemampuan DPRD dalam pembentukan peraturan daerah menjadi kurang efektif.

Dilihat dari keseluruhan anggota DPRD garut yang berlatarbelakang pendidikan yang tahu akan pembuatan RUU hanya beberapa orang saja.

\section{b. Pengalaman}

Faktor pengalaman menjadi salah satu faktor yang mempengaruhi DPRD dalam melaksanakan fungsi legislasi. Pengalamanlah yang banyak mempengaruhi kineja setiap anggota DPRD

Minimnya pengalaman yang dimiliki oleh anggota DPRD dalam merumuskan RUU menyebabkan anggota DPRD mendapatkan kesulitan dalam pembahasan tersebut. Terutama bagi anggota DPRD yang baru berkecimpung di dunia legislasi. Pengalaman tersebut sangat berpengaruh terhadap tugas anggota DPRD, dengan pengalaman DPRD dapat mengetahui bagaimana dan harus berbuat apa dalam bersikap menghadapi sebuah masalah.

Pengalaman anggota DPRD yang pernah duduk di lembaga legislatif pada periode sebelumnya, kinerja dan hasil perda yang dihasilkan akan lebih baik di bandingkan dengan anggota DPRD yang baru menduduki lembaga legislatif.

Berdasarkan pernyataan dari berbagai informan bahwa pengalaman merupakan faktor yang domiann dalam mempengaruho kemampuan anggota DPRD Kabupaten Garut dalam menjalankan fungsi legislasinya, Karena dngan pengalaman nya itu anggota DPRD dapat menggali infotrmasi yang berkualitas, valid, dan dapat memanfaatkan informasi yang ada secara lebih tepat, sehingga melakukan kebijakan yang tepat juga.

\section{Rekrutmen Calon Legislatif}

Dalam rekrutmen calon anggota legislatif yang dilakukan partai politik biasanya tidak melihat dari kualitas orang nya tetapi memperhatikan aspek loyalitas saja. Hal tersebut yang biasa dilakukan semua partai politik.

Partai harus mengubah gaya nekat dalam pencalonan. Dalam kenyataan nya pemilu 2014 banyak partai asal 'mencomot' caleg mereka tanpa sebuah mekanisme berjenjang. Jelang pemilu banyak yang mendadak nyaleg. Terlebih jika caleg yang bersangkutan punya sumber daya yang kerap 'merangsang' partai untuk mendekatinya. Sejumlah sumber daya tersebut ialah popularitas, uang, dan akses terhadap opini media massa.

Popularitas dimiliki para selebritas yang terbiasa mendapatkan ruang berita di media massa. Basis nyata simpul suara biasanya diidentikkan dengan tokoh organisasi masyarakat, tetua adat, agamawan, yang kesehariannya penetratif ke basis-basis pemilih.

Uang dan akses biasanya menjadi alat nego para pengusaha yang kerap berminat nyaleg untuk proteksi bisnis mereka. Terakhir, konstruksi opini di media melibatkan human agency seperti pekerja media atau orang yang mengendalikan media. Makanya, jangan heran kalau di deretan caleg dengan mudah kita menemukan deretan nama jurnalis atau mantan jurnalis.

Sesungguhnya yang membuat publik pesimistis bukan pada latar belakang profesi mereka, karena sesungguhnya setiap warga negara memiliki hak memilih dan dipilih yang melekat pada dirinya. Semua orang dengan beragam latar belakang profesinya harus dihormati saat berminat untuk berpartisipasi dalam pencalegan.

Yang patut diberi catatan kritis sesungguhnya ialah model dadakan dalam pencalegan. Menjadi wakil rakyat itu amanah kekuasaan yang sangat serius. Jabatan tersebut tak layak dipegang sejumlah orang yang sedang belajar, coba-coba, atau sekadar berpetualang. Perlu kesungguhan dalam penyiapan diri sebelum mereka terpilih menjadi wakil rakyat.

Menjadi caleg bukan lahan mencari pekerjaan, karena substansi jabatan itu untuk dedikasi dan pengabdian mewakili sejumlah basis konstituen. Setiap caleg yang diajukan partai seharusnya memiliki kompetensi intelektual, moral dan sosial. Partai seharusnya bukan semata mendistribusikan orang, melainkan memiliki tanggung jawab untuk melakukan rekrutmen, menyamakan nilai-nilai dan ideologi partai, serta melihat rekam jejak setiap caleg mereka. Tahapan penyiapannya tak cukup asal-asalan. Butuh sebuah sistem berjenjang dan berkelanjutan untuk mengumpulkan sejumlah nama yang benar-benar layak.

\section{Tata tertib mekanisme kerja}

Berdasarkan hasil wawancara dengan salasatu anggota DPRD Garut bahwa yang menjadi kendala dalam mekanisme kerja DPRD Kabupaten Garut adalah banyaknya pekerjaan yang telah di jadwalkan belum terlaksana hal tersebut disebabkan karena tidak ada kedisiplinan kerja anggota DPRD kabupaten Garut, seperti halnya dalam rapat pembahasan dan pengesahan peraturan daerah jumlah anggota DPRD harus hadir kurang dari 50\% namun pada kenyataannya anggota DPRD yang hadir kurang 50\% sehingga mengakibatkan rapat paripurna tidak bisa dilaksanakan walaupun di hadiri ketua DPRD karena menyalahi aturan suara dalam mengambil keputusan DPRD. Hal ini tentu berdampak terhadap waktu dala pembahasan dan pembahasan yang diundur.

Terkait hal tersebut dapat dilihat bahwa tidak ada ketaatan anggota DPRD Kabupaten Garut dalam mematuhi tata terbit yang berlaku sehingga berimbas pada jadwal legislasi yang sudah di tetapkan karena jumlah anggota DPRD yang hadir tidak sesuai dengan porsinya.

\section{Kerja sama Antar anggota DPRD}

Faktor kerja sama antar anggota DPRD juga sangat mempengaruhi dalam penyusunan suatu rancangan Perda . Dala hal ini kerjasama yang dilakukan diantar anggota dewan hendaknnya tidak semata-mata 
atas dasar kepentingan kelompok (partai politik) tetapi lebih mengkedepankan kepentingan masyarakat, yang telah memberikan mandate kepada anggota DPRD dalam membuat dan menghasilkan kebijakan dengan tujuan untuk kesejahteraan rakyat.

\section{Kurang nya tenaga Ahli}

PP Nomor 12 Tahun 2018 tentang peraturan tata tertib DPRD Provinsi dan Kabupaten/Kota menyatakan bahwa Sistem Pendukung DPRD Kabupaten Garut pasal 168 tentang Kelompok Pakar atau Tenaga Ahli DPRD yaitu : a. Dalam rangka melaksanakan tugas dan wewenang DPRD dibentuk kelompok pakar atau tenaga ahli; b. Kelompok pakar atau tenaga ahli sebagaimana dimaksud ayat (1) diangkat dan diberhentikan dengan keputusan sekretaris DPRD sesuai dengan kebutuhan atas usul anggota DPRD melalui fraksi dan kemampuan daerah; c. Kelompok pakar atau tenaga ahli sebagaimana dimaksud pada ayat (1)bekerja sesuai dengan pengelompokan tugas dan wewenang DPRD yang tercermin dalam alat kelengkapan DPRD. Berdasarkan hasil wawancara dengan bagian perundang-undangan DPRD Kabupaten Garut mengatakan bahwa ; Kita memiliki tenaga ahli, namun hanya bagian fraksi yang secara SK ada tertera, namun kalau tenaga ahli bagian pembentukan peraturan daerah kita tidak punya, tetapi disini ada istilah Publing Hearing atau tenaga ahli yang sengaja kita undang pada saat pelaksanaan rapat pembahasan perda. Dan tenaga ahli ini kita sesuaikan dengan 67 pembahasan perda, misalnya perda tentang hukum, ya orang akademis bidang hukum yang kita undang seperti dari fakultas hukum universitas Padjajaran, dan univeristas-universitas yang ada di Garut, begitu juga halnya dengan pembahasan perda tentang sosial, pasti orang sosial yang kita undang. Tenaga ahli sangat dibutuhkan untuk memberikan masukan terhadap peraturan daerah yang telah dirumuskan oleh anggota Dewan, berdasarkan hasil masukan dari tenaga ahli yang berasal dari akademisi Universitas yang ada di Kota Garut nantinya menjadi bekal anggota dewan dalam pembahasan perda dengan Walikota atau badan Eksekutif. Namun berdasarkan hasil wawancara dengan ketua bagian perundangundangan DPRD Kabupaten Garut mengatakan bahwa mereka tidak memiliki tenaga ahli tetap dikarenakan terbentur dengan masalah anggaran. Anggraan DPRD tidak akan cukup untuk membayar terus menerus tenaga ahli, maka dari itu kita punya inisiatif hanya mengundang tenaga ahli pada saat pembahasan peraturan daerah, mengingat peran tenaga ahli sangat dibutuhkan dalam pembentukan produk hukum daerah atau peraturan daerah sebelum di bahas dengan badan eksekutif dan di sahkan menjadi peraturan daerah. Sumbangsih tenaga ahli dalam pembentukan sebuah perda sangat diharapkan, karena sebuah perda yang dirumuskan belum tentu sesuai dengan apa yang diinginkan. Menurut ketua bagian perundang- undangan, tenaga ahli juga bisa dikatakan mewakili masyarakat, karena masukan dari mereka selalu independent dan mewakili masyarakat.

\section{Simpulan dan Saran Simpulan}

Dalam fungsi legislasi DPRD memiliki fungsi membuat peraturan daerah, melalui fungsi ini DPRD berada pada posisi yang sangat berpengaruh terhadap kelangsungan masa depan daerah , maka dari itu dalam pelaksanaan fungsi legislasi ini di perlukan produktifitas DPRD yang maksimal. Tetapi dalam kenyataan nya fungsi ini tidak berjalan maksimal . DPRD kabupaten Garut dinilai kurang produktif karena sedikitnya Rancangan Perda yang diajukan atas inisiatif dewan. Kurangnya Kinerja DPRD terlihat dari produk legislasinya. Faktor-faktor yang mempengaruhi produktifitas DPRD dalam melakasanakan fungsi legislasi diantaranya Sumber Daya Manusia baik di tingkat pendidikan maupun pengalaman dinilai kurang , karena banyak para anggota DPRD Garut pada periode 2014-2019 bukan berlatar pendidikan hukum artinya banyak anggota DPRD yang tidak mengetahui bagaimana cara membuat Rancangan Perda, kemudian dari segi pengalaman juga anggota DPRD Garut dianggap kurang bisa mengakomodir aspirasi masyarakat sehingga DPRD kurang memahami fenomena social yang ada di masyarakat, karena dalam pembentukan Perda harus mengetahui betul bagaimana kondisi social,ekonomi, politik dan budaya yang selalu berubah dan berkembang dimasyarakat sehingga perda tersebut bisa berguna bagi kepentingan masyarakat.

Faktor lainnya yaitu dalam rekrutmen calon legislatif, karena pada kenyataan partai politik memilih caleg tidak melihat kualitas seseorang melainkan karena loyalitas saja hal tersebut mengakibatkan para calon legislative yang di pilih partai politik diragukan kemampuannya. Selain itu faktor kerja sama antar anggota DPRD diperlukan dalam penyusunan perda. Para anggota DPRD membuat Perda cenderung mengedaepankan kepentingan partai politik dibandingkan kepentingan masyarakat. Kurangnya tenaga ahli juga berpengaruh terhadap pembuatan perda karena keterbatasan kemampuan yang dimiliki anggota DPRD garut dalam membuat produk hukum sehinnga memerlukan bantuan dari para ahli tentang hukum.

\section{Saran}

Untuk memaksimalkan fungsi legislasi agar DPRD kabupaten Garut bisa lebih produktif seharus nya walaupun para anggota DPRD sedikit yang berlatar belakang hukum seharusnya lebih inisiatif dengan cara banyak belajar dan berlatih dalam merancang Perda karena apabila mengandalkan dan di 
bantu terus menurus oleh para ahli maka akan menghabiskan anggaran uang yang tidak sedikit.

\section{Daftar Pustaka}

\section{Buku:}

Apter, David E. 1985. Pengantar Analisa Politik. Jakarta : CV Rajawali.

Assidiqie, Jimly. 2009. Pengantar Ilmu Hukum Tata Negara. Jakarta : PT Raja Grafindo Persada.

Budiarjo, Miriam. 1989. Dasar-dasar Ilmu Politik, Jakarta : PT Gramedia.

\section{Jurnal dan Makalah:}

Arifuddin N.2016. Fungsi Dewan Perwakilan Rakyat Daerah ( Legal pluralism : volume 6 nomor 2

Sulistyowati, Kinerja Anggota DPRD Provinsi Jawa Tengan Periode 2009-2014

Solihah, Ratnia. 2016. “ Pelaksanaan Fungsi Legislasi Dewan Perwakilan Rakyat Pasca Pemilu 2014: Permasalahan dan upaya mengatasinya"

\section{Internet:}

file://C:/Users/User/Downloads/PELAKSANA

FUNGSI_LEGISLASI_DEWAN_PERWA.p

df diakses pada 18 Juni 2019

https://muchsinal-

mancaki.blogspot.com/2011/09/fungsi-

legislasi-dpr.html di akses pada 16 Juni 2019 